\title{
Kinetics and mechanism of oxidation of chloramphenicol by 1-chlorobenzotriazole in acidic medium
}

\author{
R C HIREMATH, R V JAGADEESH, PUTTASWAMY and S M MAYANNA* \\ Department of Post-Graduate Studies and Research in Chemistry, Central College Campus, \\ Bangalore University, Bangalore 560 001, India \\ e-mail: smm_chem@yahoo.co.in
}

MS received 18 October 2004; revised 25 May 2005

\begin{abstract}
Chloramphenicol (CAP) is an antibiotic drug having a wide spectrum of activity. The kinetics of oxidation of chloramphenicol by 1-chlorobenzotriazole (CBT) in $\mathrm{HClO}_{4}$ medium over the temperature range 293-323 K has been investigated. The reaction exhibits first-order kinetics with respect to [CBT] and zero-order with respect to $[\mathrm{CAP}]_{\mathrm{o}}$. The fractional-order dependence of rate on $\left[\mathrm{H}^{+}\right]$suggests complex formation between CBT and $\mathrm{H}^{+}$. It fails to induce polymerization of acrylonitrile under the experimental conditions employed. Activation parameters are evaluated. The observed solvent isotope effect indicates the absence of hydride transfer during oxidation. Effects of dielectric constant and ionic strength of the medium on the reaction rate have been studied. Oxidation products are identified. A suitable reaction scheme is proposed and an appropriate rate law is deduced to account for the observed kinetic data.
\end{abstract}

Keywords. Chloramphenicol; 1-chlorobenzotriazole; oxidation; kinetics.

\section{Introduction}

Chloramphenicol (chloromycetin; D-(-)-threo-2-dichloroacetamido-1-p-nitrophenyl propane-1,3-diol; CAP) being an antibiotic finds applications in combating a wide range of infections. CAP undergoes hydrolysis in strong acidic and alkaline media at elevated temperature. ${ }^{1}$ Oxidative method of assay of CAP in pharmaceutical formulations has been developed $^{2}$ and an aldehyde has been identified as the oxidation product of CAP with ozone-air mixture. ${ }^{3}$ Review of the literature reveals meagre information about the oxidation kinetics of CAP. 1-chlorobenzotriazole (CBT) is a versatile oxidizing agent and its solution chemistry is reasonably well understood. ${ }^{4}$ Kinetics of oxidation of CAP by CBT in alkaline medium has been studied in our laboratory and the reaction is found to be slow ${ }^{5}$. However, no such report is available in acid media. The kinetic aspects of oxidation of dimethylamine by $\mathrm{CBT}^{6}$ are also reported. There are a few reports on the kinetics of oxidation of medicinal compounds by $\mathrm{CBT}^{7-9}$ With this background, we report here results pertaining to the kinetics and mechanism of oxidation of CAP by

*For correspondence
CBT in $\mathrm{HClO}_{4}$ medium at $323 \mathrm{~K}$ for elucidating the mechanism of oxidation of this drug.

\section{Experimental}

Chloramphenicol (Sigma, USA) was purified before use. CBT was prepared and purified as reported earlier. ${ }^{10}$ AnalaR grade chemicals and double distilled water was used throughout the studies. Solvent isotope studies were made with heavy water $\left(\mathrm{D}_{2} \mathrm{O}\right.$, 99.4\% isotopic purity) supplied by the Bhabha Atomic Research Centre, Mumbai.

\section{$2.1 \quad$ Kinetic measurements}

Kinetic runs were performed under pseudo-firstorder conditions with excess of the CAP over the oxidant at $323 \mathrm{~K}$. The reaction was carried out in stoppered Pyrex boiling glass tubes, whose outer surfaces were coated black to eliminate photochemical effects. For each run, requisite amount of solutions of substrate, $\mathrm{HClO}_{4}, \mathrm{NaClO}_{4}$ and water (to maintain a constant volume) were measured and thermally equilibrated at $323 \mathrm{~K}$. A measured amount of the CBT solution, also equilibrated at the same temperature, was rapidly added to the reaction mix- 
ture in the boiling tube with stirring. The progress of the reaction was monitored by iodometric determination of unreacted oxidant in measured aliquots ( $5 \mathrm{ml}$ each) of the reaction mixture withdrawn at different intervals of time. The course of the reaction was studied for at least two half-lives. Pseudo-firstorder rate constant, $k$, calculated from the linear plots of $\log$ [oxidant] vs time were reproducible within $\pm 3 \%$. Regression analysis of the experimental data were carried out using an fx-100W scientific calculator to obtain the regression coefficient, $r$.

\subsection{Stoichiometry and product analysis}

Different sets of concentrations of the reactants in $0.1 \mathrm{~mol} \mathrm{dm}^{-3}$ perchloric acid were kept for over $24 \mathrm{~h}$ at $323 \mathrm{~K}$. The determination of unconsumed CBT in the reaction mixture showed that one mole of CAP consumed a mole of CBT (table 1). The observed stoichiometry is as shown below,
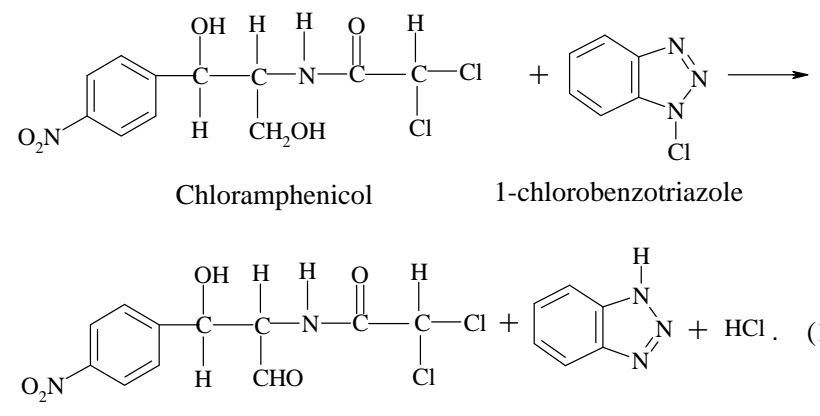

$$
\begin{aligned}
& \text { D(-)-threo-2-dichloroacetamido-1- Benzotriazole } \\
& \text { nitorphenyl-1-hydroxy-3-propnal }
\end{aligned}
$$

The reduction product of CBT, benzotriazole (BTA), was isolated and identified ${ }^{11}$ by TLC using butanolacetic acid-water $(4: 1: 1 \mathrm{v} / \mathrm{v})$ as solvent and iodine as the detecting agent $\left(R_{f}=0.93\right)$. The obtained $R_{f}$ value was consistent ${ }^{11}$ with the literature value. The main product (aldehyde) was the same under different experimental conditions (table 1). The aldehyde was confirmed by IR spectra which show bands at $3440 \mathrm{~cm}^{-1}$ and $1720 \mathrm{~cm}^{-1}$ for $\mathrm{OH}$ stretching and $\mathrm{C}=\mathrm{O}$ stretching respectively and a band at $2720 \mathrm{~cm}^{-1}$ for aldehydic $\mathrm{C}-\mathrm{H}$ stretching. The aldehyde was also

Table 1. Stoichiometry of oxidation of CAP by CBT.

\begin{tabular}{lllll}
\hline $10\left[\mathrm{HClO}_{4}\right] / \mathrm{M}$ & $0 \cdot 1$ & 0.25 & 0.50 & 1.0 \\
$\Delta[\mathrm{CBT}] / \Delta[\mathrm{CAP}]$ & 0.95 & 0.98 & 0.97 & 1.0 \\
$\Delta[\mathrm{CBT}] / \Delta[\mathrm{CAP}]$ & 0.97 & 0.99 & 0.96 & 0.99 \\
\hline
\end{tabular}

identified as its 2,4-dinitrophenylhydrazone derivative.

\section{Results}

Oxidation of CAP by CBT in aqueous solution is very slow ${ }^{5}$ and becomes appreciable only in the presence of $\mathrm{H}^{+}$ions and at higher temperature. Hence, detailed kinetic investigations of oxidation of CAP by CBT were made in $0.1 \mathrm{~mol} \mathrm{dm}^{-3} \mathrm{HClO}_{4}$ solution at $323 \mathrm{~K}$.

With the substrate in excess at constant $[\mathrm{CAP}]_{\mathrm{o}}$, $\left[\mathrm{HClO}_{4}\right]$ and temperature, plots of $\log [\mathrm{CBT}]$ vs time were linear $(r>0.9850)$ indicating first-order dependence of rate on $[\mathrm{CBT}]_{\mathrm{o}}$. The pseudo-firstorder-rate constant $(k)$ was independent of $[\mathrm{CBT}]_{\text {o }}$ (table 2), confirming the first-order dependence on $[\mathrm{CBT}]_{\mathrm{o}}$. Values of $k$ did not change with increase in $[\mathrm{CAP}]_{\mathrm{o}}$ (table 2), indicating zero-order dependence of the reaction rate on $[\mathrm{CAP}]_{\mathrm{o}}$. The rate increased with increase in $\left[\mathrm{HClO}_{4}\right]$ and the linear plot of $\log k$ vs $\log \left[\mathrm{HClO}_{4}\right](r=0.9810)$ with a slope of 0.62 indicated fractional-order dependence of the reaction rate on $\left[\mathrm{HClO}_{4}\right]$ (table 2). Further, a plot of $1 / k$ vs $1 /\left[\mathrm{H}^{+}\right](r=0.9870)$ gives a straight line, with a $y$ intercept, confirming fractional-order dependence on $\left[\mathrm{H}^{+}\right]$.

Table 2. Effect of varying CBT, CAP and $\mathrm{HClO}_{4}$ con-

\begin{tabular}{|c|c|c|c|}
\hline $\begin{array}{l}10^{4}[\mathrm{CBT}]_{\mathrm{o}} \\
\left(\mathrm{mol} \mathrm{dm}^{-3}\right)\end{array}$ & $\begin{array}{l}10^{3}[\mathrm{CAP}]_{\mathrm{o}} \\
\left(\mathrm{mol} \mathrm{dm}^{-3}\right)\end{array}$ & $\begin{array}{l}10\left[\mathrm{HClO}_{4}\right] \\
\left(\mathrm{mol} \mathrm{dm}^{-3}\right)\end{array}$ & $k \times 10^{4}\left(\mathrm{~s}^{-1}\right)$ \\
\hline $1 \cdot 0$ & $5 \cdot 0$ & $1 \cdot 0$ & $3 \cdot 05$ \\
\hline $2 \cdot 5$ & 5.0 & $1 \cdot 0$ & $3 \cdot 15$ \\
\hline $5 \cdot 0$ & 5.0 & $1 \cdot 0$ & $3 \cdot 00$ \\
\hline $7 \cdot 5$ & 5.0 & $1 \cdot 0$ & 2.98 \\
\hline $10 \cdot 0$ & 5.0 & $1 \cdot 0$ & $3 \cdot 10$ \\
\hline 1.0 & 1.0 & 1.0 & $3 \cdot 12$ \\
\hline $1 \cdot 0$ & 2.5 & $1 \cdot 0$ & $3 \cdot 08$ \\
\hline $1 \cdot 0$ & 5.0 & 1.0 & 3.05 \\
\hline $1 \cdot 0$ & 7.5 & $1 \cdot 0$ & 3.09 \\
\hline $1 \cdot 0$ & $10 \cdot 0$ & $1 \cdot 0$ & $3 \cdot 14$ \\
\hline $1 \cdot 0$ & 5.0 & $0 \cdot 10$ & 0.65 \\
\hline 1.0 & $5 \cdot 0$ & $0 \cdot 25$ & 1.25 \\
\hline $1 \cdot 0$ & $5 \cdot 0$ & 0.50 & $2 \cdot 15$ \\
\hline $1 \cdot 0$ & $5 \cdot 0$ & $1 \cdot 0$ & $3 \cdot 05$ \\
\hline $1 \cdot 0^{\mathrm{a}}$ & $5 \cdot 0$ & 1.0 & 3.07 \\
\hline $1 \cdot 0^{\mathrm{b}}$ & $5 \cdot 0$ & 1.0 & $2 \cdot 90$ \\
\hline $1 \cdot 0^{\mathrm{c}}$ & $5 \cdot 0$ & 1.0 & $2 \cdot 17$ \\
\hline $1 \cdot 0^{\mathrm{d}}$ & $5 \cdot 0$ & 1.0 & $5 \cdot 10$ \\
\hline
\end{tabular}
centrations on the reaction rate at $323 \mathrm{~K}$. 
Addition of the reaction product, benzotriazole $\left(1.0 \times 10^{-3} \mathrm{~mol} \mathrm{dm}^{-3}\right)$ and variation of ionic strength of the medium $\left(0 \cdot 1-0.5 \mathrm{~mol} \mathrm{dm}^{-3}\right)$ by adding $\mathrm{NaClO}_{4}$ have no significant effect on the rate of reaction. Hence, no attempt was made to keep the ionic strength of the reaction mixture constant for the kinetic runs. Addition of tertiary butanol decreased the rate of reaction. Solvent isotope effect was studied using $\mathrm{D}_{2} \mathrm{O}$. The reaction rate is increased with $k=5.10 \times 10^{-4} \mathrm{~s}^{-1}$ in $\mathrm{D}_{2} \mathrm{O}$ and $k=3.05 \times 10^{-4} \mathrm{~s}^{-1}$ in $\mathrm{H}_{2} \mathrm{O}$, leading to a solvent isotope effect $k\left(\mathrm{H}_{2} \mathrm{O}\right) / k$ $\left(\mathrm{D}_{2} \mathrm{O}\right)=0 \cdot 60$. All these results are reported in table 2 .

The reaction was studied at different temperatures (293-323 K). Rate constants at 293, 303, 313 and $323 \mathrm{~K}$ were found to be $0.32,0.65,1.45,3.05 \times 10^{-4} \mathrm{~s}^{-1}$ respectively. From the linear Arrhenius plot ( $r=0.9993)$ of $\log k$ vs $1 / T$, the computed activation parameters for the overall reaction were evaluated: $E_{a}=55.8 \mathrm{~kJ} \mathrm{~mol}^{-1} ; \Delta H^{\#}=53.2 \mathrm{~kJ} \mathrm{~mol}^{-1} ; \Delta G^{\#}=101$ $\mathrm{kJ} \mathrm{mol}^{-1}$ and $\Delta S^{\#}=-149 \mathrm{JK}^{-1} \mathrm{~mol}^{-1}$. Addition of acrylonitrile to the reaction mixture had no effect, indicating the absence of free radical species during the reaction.

\section{Discussion}

The hydrolysis of CAP under the present experimental conditions is negligible. ${ }^{1}$ This is further confirmed by testing the absence of free base $\left(-\mathrm{NH}_{2}\right.$ group) in the reaction mixture using the reduced form of ninhydrin. ${ }^{12} \mathrm{CBT}$ being $\mathrm{N}$-haloamine gives several oxidizing species in aqueous solution. ${ }^{13}$ The concentration of each species depends on the concentration of CBT, the nature (polar or non-polar) and $\mathrm{pH}$ of the medium. Benzotriazole (BTA), the parent compound of CBT, has $\mathrm{p} K_{b} 5 \cdot 8$ and hence it might largely exist in protonated form in an aqueous solution, ${ }^{13}$

$$
\mathrm{CBT}+\mathrm{H}_{3} \mathrm{O}^{+} \rightleftharpoons \mathrm{CBTH}^{+}+\mathrm{H}_{2} \mathrm{O} \text {. }
$$

Because of the weakening of the $\mathrm{N}-\mathrm{Cl}$ bond, it might solvalize further to give $\mathrm{H}_{2} \mathrm{OCl}^{+}$,

$$
\mathrm{CBTH}^{+}+\mathrm{H}_{2} \mathrm{O} \rightleftharpoons \mathrm{BTA}+\mathrm{H}_{2} \mathrm{OCl}^{+} \text {. }
$$

If $\mathrm{H}_{2} \mathrm{OCl}^{+}$is the active oxidant species, a retardation of rate by added BTA is expected. However, no such effect was noticed (table 2) in the present investigation and hence the possibility of $\mathrm{H}_{2} \mathrm{OCl}^{+}$as the oxidizing species is ruled out. In order to establish this point, some kinetic experiments were carried out with $\mathrm{CBT}$ and $\mathrm{HOCl}$ under comparable experimental conditions. The kinetic data with $\mathrm{HOCl}$ and CBT were not the same $\left(k_{\mathrm{HOCl}}=4.35 \times 10^{-6} \mathrm{~s}^{-1}\right.$ and $\left.k_{\mathrm{CBT}}=3 \cdot 15 \times 10^{-4} \mathrm{~s}^{-1}\right)$. Hence, the reactive oxidizing species could be $\mathrm{CBTH}^{+}$which accounts for the observed fractional-order dependence of rate on $\left[\mathrm{H}^{+}\right]$. Such an argument was also proposed earlier ${ }^{14}$ for the oxidation of benzyl alcohol by CBT. In view of these facts, the reaction scheme 1 can be proposed to account for the observed kinetics in the oxidation of CAP by CBT in acidic medium:

The probable structure of the intermediate complex $(\mathrm{X})$ is as below:<smiles>O[N+]1(Cl)NNc2ccccc21</smiles>

The total effective concentration of CBT is $[\mathrm{CBT}]_{\mathrm{t}}$, then

$$
[\mathrm{CBT}]_{\mathrm{t}}=[\mathrm{CBT}]+\left[\mathrm{CBTH}^{+}\right],
$$

From step (i) of scheme 1,

$$
[\mathrm{CBT}]=\frac{\left[\mathrm{CBTH}^{+}\right]}{K_{1}\left[\mathrm{H}^{+}\right]} .
$$

By substituting for [CBT] in (4), we get

$$
[\mathrm{CBT}]_{\mathrm{t}}=\frac{\left[\mathrm{CBTH}^{+}\right]}{K_{1}\left[\mathrm{H}^{+}\right]}+\left[\mathrm{CBTH}^{+}\right]
$$

or

$$
\left[\mathrm{CBTH}^{+}\right]=\frac{K_{1}[\mathrm{CBT}]_{\mathrm{t}}\left[\mathrm{H}^{+}\right]}{1+K_{1}\left[\mathrm{H}^{+}\right]} .
$$

$$
\begin{array}{lr}
\mathrm{CBT}+\mathrm{H}^{+} \underset{(\mathrm{i})}{\stackrel{K_{1}}{\rightleftharpoons}} \mathrm{CBTH}^{+}, & \text {fast, } \\
\mathrm{CBTH}^{+}+\mathrm{H}_{2} \mathrm{O} \underset{\text { (ii) }}{\stackrel{k_{1}}{\longrightarrow}} \mathrm{X}, & \text { slow and rds, } \\
\mathrm{X}+\mathrm{CAP} \underset{\text { (iii) }}{\stackrel{k_{2}}{\longrightarrow} \text { products. }} \quad \text { fast. }
\end{array}
$$

Scheme 1. 
From the slow step of scheme 1,

$$
\text { rate }=-d[\mathrm{CBT}]_{\mathfrak{t}} / \mathrm{d} t=k_{1}\left[\mathrm{CBTH}^{+}\right]\left[\mathrm{H}_{2} \mathrm{O}\right] \text {. }
$$

By substituting for $\left[\mathrm{CBTH}^{+}\right]$from (5) into (6), the following rate law is obtained.

$$
\text { rate }=\frac{K_{1} k_{1}[\mathrm{CBT}]_{\mathrm{t}}\left[\mathrm{H}^{+}\right]}{1+K_{1}\left[\mathrm{H}^{+}\right]} .
$$

The above rate law is in agreement with the observed kinetic results.

Since rate $=k^{\prime}[\mathrm{CBT}]_{\mathrm{t}},(7)$ can be transformed into,

$$
\begin{aligned}
& \frac{1}{k^{\prime}}=\frac{1+k_{1}\left[\mathrm{H}^{+}\right]}{K_{1} k_{1}\left[\mathrm{H}^{+}\right]}, \\
& \frac{1}{k^{\prime}}=\frac{1}{K_{1} k_{1}\left[\mathrm{H}^{+}\right]}+\frac{1}{k_{1}} .
\end{aligned}
$$

From the linear double reciprocal plot of $1 / k$ vs $1 /$

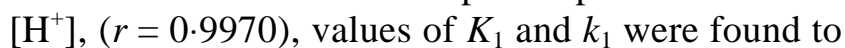
be $16.4 \mathrm{dm}^{3} \mathrm{~mol}^{-1}$ and $4.54 \times 10^{-4} \mathrm{dm}^{3} \mathrm{~mol}^{-1} \mathrm{~s}^{-1}$ respectively.

Solvent isotope studies in $\mathrm{D}_{2} \mathrm{O}$ medium show an increase in the reaction rate. It is well known that $\mathrm{D}_{3} \mathrm{O}^{+}$is a stronger acid ${ }^{15}$ than $\mathrm{H}_{3} \mathrm{O}^{+}$and hence this observation supports the proposed mechanism. The negligible effect of BTA on the rate of reaction indicates that it was not involved in pre-equilibrium. The change in the ionic strength of the medium did not alter the rate indicating that non-ionic species were involved in the rate determining step. A slight negative dielectric constant effect on the rate supports the fact that the dipole interaction in the rate determining step. ${ }^{16}$ The proposed mechanism is supported by the moderate values of energy of activation and other thermodynamic parameters. The fairly high positive values of free energy of activation and enthalpy of activation indicate that the tran- sition state is highly solvated, while the high negative entropy of activation suggests the formation of the compact activated complex with fewer degrees of freedom.

The stoichiometry, products and kinetic results are different in acidic and alkaline ${ }^{5}$ media. Energy of activation revealed that the reaction is found to be faster in acid medium compared to alkaline medium $\left(E_{a}\right.$ in alkaline medium is $\left.59.0 \mathrm{~kJ} \mathrm{~mol}^{-1}\right){ }^{5}$ This may be due to the involvement of different reactive species of $\mathrm{CBT}$ in acidic $\left(\mathrm{CBTH}^{+}\right)$and alkaline $\left(\mathrm{OCl}^{-}\right)$ media of this redox system.

\section{References}

1. Rebstock M C, Crooks H M, Controulis Jr J and Bartz Q R 1949 J. Am. Chem. Soc. 712458

2. Jayaram B and Mayanna S M 1983 Talanta 30798

3. Galstyan G A, Galstyan T M and Yakobi V A 1990 Ukr. Uknin. Zh. $\mathbf{4 2} 738$

4. Hiremath R C, Mayanna S M and Venkatasubramanian N 1990 J. Sci. Ind. Res. 49122

5. Heremath R C, Meenakshi and Mayanna S M 2003 Oxid. Commun. 26(1) 574

6. Ulagi R, Kuselan P and Karunakaran C $2002 \mathrm{~J}$. Chem. Sci. 56(2) 123

7. Nanda N, Mayanna S M and Gowda N M M 1990 Int. J. Chem. Kinet. 31153

8. Nanda N and Mayanna S M 1990 Oxid. Commun. 22 107

9. Nanda N, Sheshadri B S and Mayanna S M $1990 R e$ act. Kinet. Catal. 6735

10. Johnson C R, Bacon C C and Kingsbury W D 1978 Tetrahedron Lett. 501

11. Hiremath R C and Mayanna S M 1984 Mikrochim. Acta (Wein) II 175

12. Hughes E D and Ingold C K 1952 Q. Rev. 6

13. Srinivasan N S and Venkatasubramanian N 1974 Tetrahedron Lett. 30419

14. Rangadurai A, Thiagarajan $\mathrm{R}$ and Venkatasubramanian N 1982 Indian J. Chem. B21 42

15. Collins C J and Bowman N S 1970 Isotope effects in chemical reactions (New York: Van Nostrand-Reinhold) p. 267

16. Amis E S 1966 Solvent effects on reaction rates and mechanisms (New York: Academic Press) 